\title{
Comparison of the effectiveness of a daily dose of cotrimoxazole, administered once or twice, in the treatment of murine Paracoccidioidomycosis
}

CAVALCANTE RS ${ }^{1}$, MAZA L ${ }^{1}$ LEÃO PS ${ }^{2}$, BATAH SS ${ }^{2}$, FABRO AT², MENDES RP1.

1Universidade Estadual Paulista (UNESP), Faculdade de Medicina de Botucatu, Botucatu, São Paulo - Brazil; ²Universidade de São Paulo, Faculdade de Medicina de Ribeirão Preto, Ribeirão Preto, São Paulo - Brazil.

E-mail: mip.ricardo@gmail.com

\section{INTRODUCTION}

Paracoccidioidomycosis (PCM) is systemic mycosis caused by thermodymorphic fungi of the genus Paracoccidioides. Trimethoprim-sulfamethoxazole, also called cotrimoxazole $(\mathrm{CMX})$, is one of the main therapeutic options. In the current treatment of PCM, CMX is used in the dose of $2,400 \mathrm{mg}$ of sulfamethoxazole, which corresponds to six tablets divided into two daily doses, a fact that has led to the patient's lower adherence to antifungal therapy. Experimental studies have observed that the single daily dose may be sufficient to treat PCM.

\section{OBJECTIVES}

This study aimed to evaluate the efficacy of murine PCM treatment with $\mathrm{CMX}$ administered in one and two daily doses.

\section{PATIENTS AND METHODS}

Study groups: isogenic mice of the Balb / $\mathrm{c}$ line were randomly assigned G1: healthy, uninfected control $(n=23)$

G2: infected control $(n=27)$

G3: CMX once daily after 28 days of infection $(n=25)$

G4: CMX twice a day after 28 days of infection $(n=25)$

Moments of sacrifice: 8 th, 12th, 16th and 20th week after infection

Recovery of fungi in tissues
Antibody Dosage (double immunodiffusion reaction - DID)
Lung histopathological analysis
Cumulative survival analysis at 140 days

The Kruskal-Wallis and Mann-Whitney tests were used for comparison of medians, linear regression to analyze the parameters in the successive moments of sacrifice and Kaplan-Meier for the evaluation of survival. $P$ values less than 0.05 were considered significant.

\section{RESULTS}

There was no difference in cumulative mortality between G3 and G4 $(0.0 \%$ vs $4.0 \%$, p>0.05).

Table 1. Recovery of fungi from the lungs of isogenic BALB/c mice infected with Paracoccidioides brasiliensis, according to therapeutic regimen and duration of treatment. Quantification of fungi in colony forming units per gram of tissue.

\begin{tabular}{cccc}
\hline Week & $\mathbf{G 2}$ & $\mathbf{G 3}$ & $\mathbf{G 4}$ \\
\hline $\mathbf{8} \mathbf{a}$ & $12.223,0[10.400,0-20.000,0]^{\mathrm{A}, \mathrm{a}}$ & $4.861,0[0,0-15.000,0]^{\mathrm{A}, \mathrm{ab}}$ & $1.875,0[0,0-5.000,0]^{\mathrm{A}, \mathrm{b}}$ \\
$\mathbf{1 2} \mathbf{a}$ & $10.416,5[6.000,0-12.400,0]^{\mathrm{A}, \mathrm{a}}$ & $2.933,5[0,0-11.500,0]^{\mathrm{A}, \mathrm{ab}}$ & $124,0[0,0-3.703,0]^{\mathrm{A}, \mathrm{b}}$ \\
$\mathbf{1 6} \mathbf{\underline { a }}$ & $20.000,0[5.557,0-24.443,0]^{\mathrm{A}, \mathrm{a}}$ & $3.000,0[0,0-11.250,0]^{\mathrm{A}, \mathrm{a}}$ & $6075,0[0,0-15.242,0]^{\mathrm{A}, \mathrm{a}}$ \\
\hline $\mathbf{2 0} \mathbf{a}$ & $23.750,0[5.557,0-40.000,0]^{\mathrm{A}, \mathrm{a}}$ & $0,0[0,0-6.750,0]^{\mathrm{A}, \mathrm{b}}$ & $1.605,0[0,0-12.785,0]^{\mathrm{A}, \mathrm{b}}$ \\
\hline
\end{tabular}

Table 2. Serum levels of specific antibodies determined by the reaction of double immunodiffusion in agar gel in isogenic BALB/c mice infected with Paracoccidioides brasiliensis according to the therapeutic schedule and treatment time.

\begin{tabular}{cccc}
\hline weeks & $\mathbf{G 2}$ & $\mathbf{G 3}$ & $\mathbf{G 4}$ \\
\hline $\mathbf{8} \mathbf{a}$ & $1: 2[N D-1: 2]^{\mathrm{B}, \mathrm{b}}$ & $1: 16[1: 2-1: 16]^{\mathrm{A}, \mathrm{a}}$ & $1: 4[N D-1: 4]^{\mathrm{A}, \mathrm{ab}}$ \\
$\mathbf{1 2} \mathbf{a}$ & $1: 4[1: 2-1: 4]^{\mathrm{AB}, \mathrm{a}}$ & $1: 2[N D-1: 4]^{\mathrm{AB}, \mathrm{a}}$ & $1: 2[N R-1: 8]^{\mathrm{AB}, \mathrm{a}}$ \\
$\mathbf{1 6} \mathbf{a}$ & $1: 4[1: 2-1: 4]^{\mathrm{AB}, \mathrm{a}}$ & $\mathrm{NR}[\mathrm{NR}-1: 8]^{\mathrm{AB}, \mathrm{a}}$ & $\mathrm{ND}[\mathrm{NR}-\mathrm{ND}]^{\mathrm{AB}, \mathrm{a}}$ \\
$\mathbf{2 0}$ & $1: 8[1: 4-1: 8]^{\mathrm{A}, \mathrm{a}}$ & $\mathrm{ND}[\mathrm{NR}-\mathrm{ND}]^{\mathrm{B}, \mathrm{b}}$ & $\mathrm{NR}[\mathrm{NR}-\mathrm{ND}]^{\mathrm{B}, \mathrm{b}}$ \\
\hline
\end{tabular}

Capital letters compare different weeks within a group while lower case letters compare the same weeks between groups. Different letters indicate statistically significant differences $(p<0.05)$, where a or $A>b$ or $B$ and $a b$ or $A B$ does not differ from $a$ or $A$ nor from $b$ or $B$

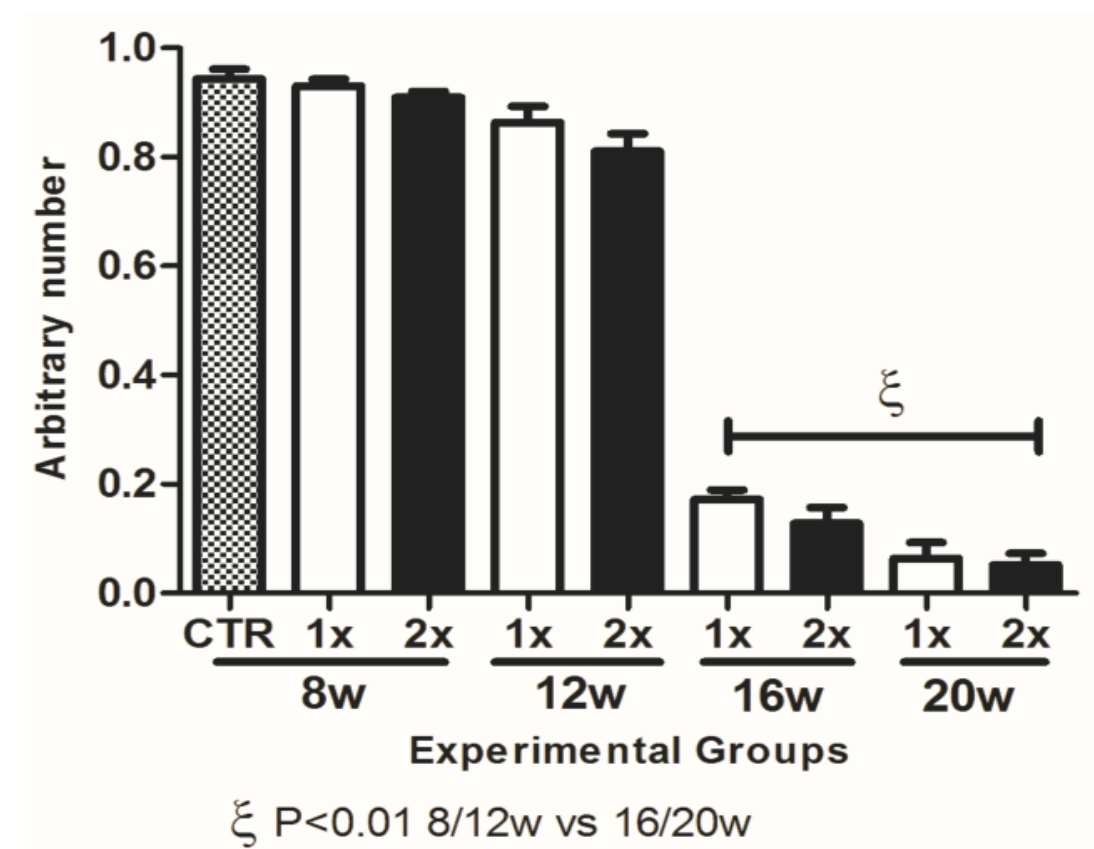

CTR - infected control group $1 \mathrm{x}$ - cotrimoxazole $200 \mathrm{mg} / \mathrm{kg} / \mathrm{day}$ (sulfamethoxazole), in single daily dose, from 28 to 140 days postinfection;

$2 x$ - cotrimoxazole $200 \mathrm{mg} / \mathrm{kg} / \mathrm{day}$ (sulfamethoxazole), in two daily doses, from 28 to 140 days postinfection.

Figure 1. Determination of the fungal load by histopathological examination of the lung by the periodic acid staining of Shiff (PAS) in male, isogenic, Balb/c mice, infected by Paracoccidioides brasiliensis, according to the therapeutic scheme used.

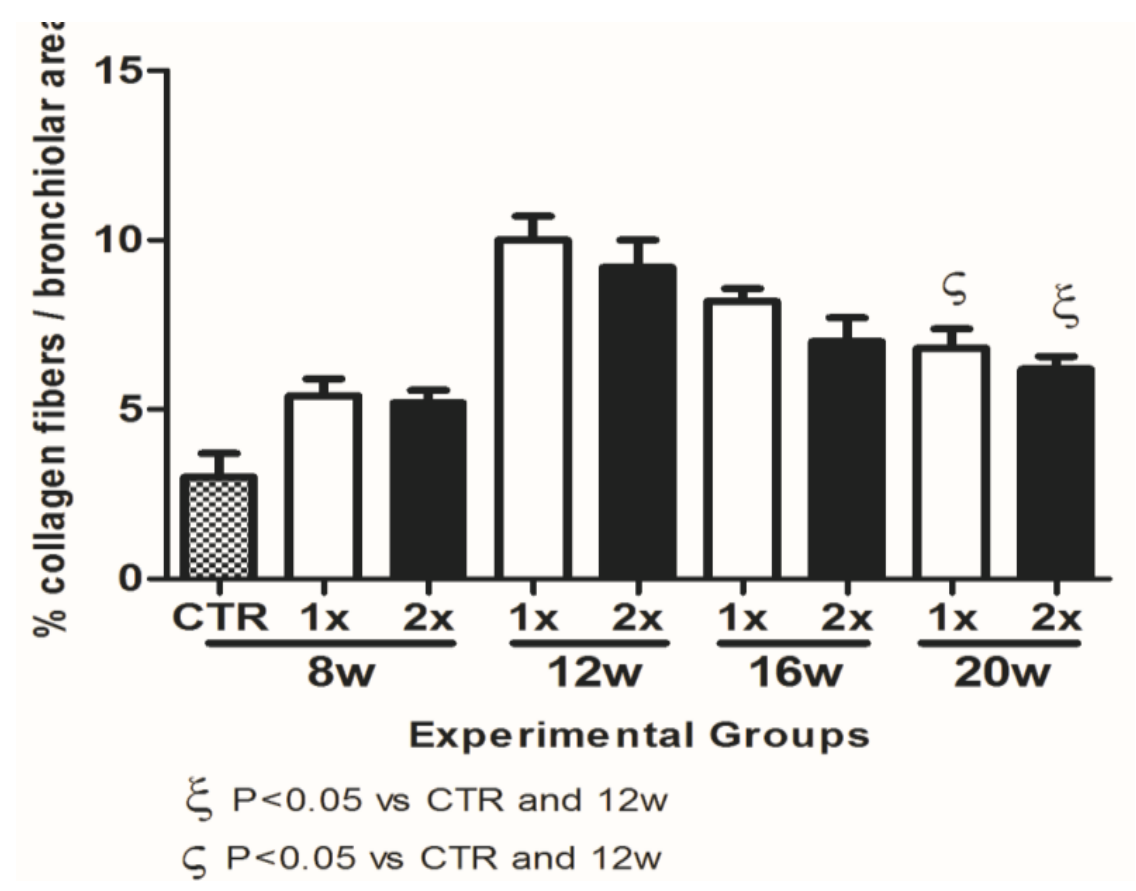

CTR - infected control group

$1 \mathrm{x}$ - cotrimoxazole $200 \mathrm{mg} / \mathrm{kg} / \mathrm{day}$ (sulfamethoxazole), in single daily dose, from 28 to 140 days postinfection;

$2 x$ - cotrimoxazole $200 \mathrm{mg} / \mathrm{kg} /$ day (sulfamethoxazole), in two daily doses, from 28 to 140 days postinfection.

$\xi \mathrm{P}<0.05$ vs CTR and $12 \mathrm{w}$

Figure 2. Percentage of collagen fibers, measured by Picrosirius staining, of lungs of male, isogenic, Balb/c mice, infected by Paracoccidioides brasiliensis, according to the therapeutic regimen used.

\section{CONGLUSION}

These findings demonstrate efficacy of the two murine PCM treatment regimens with $\mathrm{CMX}$. Although there were no direct differences between the two CMX treatment regimens, the group receiving two doses per day presented a higher response when compared to the infected control, a fact that did not occur with the single daily dose group. This suggests that differences may exist between the two schemes and that future studies are needed to better understand the efficacy of these therapeutic regimens. 